\title{
Pathology of multifocal purple spots, a nonspecific lesion morphology of Caribbean sea fans Gorgonia spp.
}

\author{
Michelle M. Dennis ${ }^{1,2, *}$, Anne A. M. J. Becker ${ }^{1}$, Mark A. Freeman ${ }^{1}$ \\ ${ }^{1}$ Center for Conservation Medicine and Ecosystem Health, Ross University School of Veterinary Medicine, St. Kitts, West Indies \\ ${ }^{2}$ Present address: Department of Biomedical and Diagnostic Sciences, University of Tennessee, College of Veterinary Medicine, \\ Knoxville, TN 37996, USA
}

\begin{abstract}
Disease is contributing to the decline of coral reefs globally, but the cause and pathogenesis of most coral diseases are poorly understood. Using Gorgonia ventalina and G. flabellum as a model for coral disease diagnosis, we histologically and microbiologically examined 45 biopsies of lesions resembling Gorgonia multifocal purple spots (MFPS) with the aim of forming a comprehensive case definition based on gross and microscopic morphologic descriptions and associated etiologies. Macroscopically, all lesions were small circular areas of purple pigmentation. Gross morphologies included pigmentation only $(4 / 45,9 \%)$, or pigmentation with branchlet expansion and fusion $(19 / 45,22 \%)$, sessile masses $(17 / 45,38 \%)$, or hard nodules $(5 / 45,9 \%)$. Histological morphologic diagnoses included amoebocyte encapsulation $(9 / 45,20 \%)$, coenenchymal amoebocytosis $(6 / 45,13 \%)$, melanin $(17 / 45,38 \%)$, and gorgonin deposition $(13 / 45,29 \%)$. Sixtyfour percent of instances of fungi and $86 \%$ of labyrinthulomycetes were localized to grossly normal portions of the biopsy, whereas barnacles were only within lesions, and $87 \%$ of instances of algae and $82 \%$ of cyanobacteria were within lesioned area of the biopsy. Penicillium $(n=12)$ was the predominant genus of fungi isolated from biopsies. Barnacles were identified as Conopea sp. using molecular techniques. The pathology and etiology underlying MFPS lesions are diverse, consistent with a highly nonspecific lesion pattern rather than a specific disease. This study demonstrates the importance of microscopic examination of tissues for accurate classification of coral diseases and lesion patterns.
\end{abstract}

KEY WORDS: Copepoda - Conopea $\cdot$ Coral disease $\cdot$ Fungus · Microbiology - Octocoral · Pathology $\cdot$ Sea fan

\section{INTRODUCTION}

Coral reefs are declining globally (Wilkinson 2008). Diseases are one reason for this trend, particularly in the Caribbean basin, where coral cover has halved in recent decades (Carpenter et al. 2008, Jackson et al. 2014). The Caribbean has been regarded as a coral disease 'hot spot' because of the comparatively large number of diseases involving a wide range of coral species (Harvell et al. 2007, Weil \& Rogers 2011). Over 18 diseases have been reported, although for many of those, the pathology has not been compre-

\footnotetext{
${ }^{*}$ Corresponding author: mdenni12@utk.edu
}

hensively described and the etiology remains mostly unknown (Weil \& Rogers 2011). One deterrent from determining the cause of coral diseases has been the propensity to diagnose diseases visually without systematic assessment of cellular changes at the microscopic level (Work \& Meteyer 2014). Because visual alterations may be nonspecific, this approach creates the possibility that the same disease nomenclature be used for a number of different diseases and etiologies (Bythell et al. 2004). Moreover, a precise morphological description encompassing gross and microscopic tissue alterations is a basic and critical initial step that 
provides the groundwork for understanding new or emerging diseases and becomes the basis for the case definition used to diagnose a specific disease (Work et al. 2008).

The sea fans Gorgonia ventalina and G. flabellum are prominent soft corals among Caribbean coral reef communities. They comprise an excellent model for studying coral disease because they are plentiful and comparatively more resilient to environmental stress (Tsounis \& Edmunds 2017), whereas many stony corals are declining and itemized under the International Union for the Conservation of Nature Red List (IUCN 2019). In addition, some of their cellular and biochemical responses to injury have been described, facilitating interpretation of microscopic changes (Petes et al. 2003, Mydlarz et al. 2008, Couch et al. 2013, Kiryu et al. 2015). Finally, tissue sampling is potentially less destructive to the colony compared to hard coral tissue sampling. For example, $44 \%$ of biopsy sites from the hard coral Orbicella faveolata failed to show any regeneration after $4 \mathrm{yr}$ (Rodríguez-Martínez et al. 2016), whereas regrowth was observed within $1 \mathrm{yr}$ at the biopsy sites of $G$. ventalina (Tracy et al. 2018).

Two reported predominant diseases of sea fans are multifocal purple spots (MFPS) and aspergillosis (Weil et al. 2015). MFPS was first observed in 2015 during field studies of sea fans in Mexico, Florida, USA, and Puerto Rico (Weil et al. 2015). Affected sea fans have multifocal, small (1-4 $\mathrm{mm}$ in diameter) circular to oblong purple spots, present in small numbers or scattered throughout the entire colony (Weil \& Hooten 2008). MFPS was later recognized in several other regions of the Caribbean Sea, including Florida, Puerto Rico, Grand Cayman, Curaçao, Grenada, and St. Eustatius (Weil et al. 2015, Ivanenko et al. 2017) and because of its increased recognition considered an emerging disease (Tracy et al. 2018). Initial reports attributed the disease to protists of the Class Labyrinthulomycetes present within lesions (Petes et al. 2003, Weil \& Rogers 2011), but their causal role was questioned by their presence within apparently healthy sea fan tissue (Burge et al. 2012). Intralesional Sphaerippe sp. copepods were later demonstrated within MFPS lesions on St. Eustatius (Ivanenko et al. 2017). Further investigations supported a causal relationship between the copepod and MFPS lesions (Tracy et al. 2018). The role of labyrinthulids in the pathogenesis of MFPS and the cellular pathology of MFPS remain uncertain. Labyrinthulids are associated with periaxial melanin deposition (Petes et al. 2003) or axial splitting without other tissue changes (Burge et al. 2012). The micro- scopic lesions associated with copepod infection have not been described in detail (Ivanenko et al. 2017, Tracy et al. 2018). Thus, whether MFPS represents a single disease or a common morphological lesion pattern shared among multiple diseases is still unclear. The objective of this study was to describe the gross and microscopic lesion morphology and associated etiologies of multifocal purple spots in Gorgonia spp. on shallow reefs of the coast of St. Kitts, with the overall aim to develop a case definition.

\section{MATERIALS AND METHODS}

\subsection{Sampling}

We surveyed 3 shallow $(<6 \mathrm{~m}$ depth $)$ reefs in St. Kitts to identify Gorgonia ventalina $(\mathrm{n}=18)$ and G. flabellum $(\mathrm{n}=7)$ sea fans affected with lesions consistent with MFPS, including Potato Bay $\left(17.282^{\circ} \mathrm{N}\right.$, $62.695^{\circ} \mathrm{E} ; \mathrm{n}=17$ lesions from 7 G. ventalina and 1 G. flabellum), Timothy Reef $\left(17.277^{\circ} \mathrm{N}, 62.685^{\circ} \mathrm{E}\right.$; $\mathrm{n}=18$ lesions from $6 \mathrm{G}$. ventalina and 2 G. flabellum) in February 2018, and Turtle Beach $\left(17.282^{\circ} \mathrm{N}\right.$, $62.695^{\circ} \mathrm{E} ; \mathrm{n}=15$ lesions, from $5 \mathrm{G}$. ventalina and $4 \mathrm{G}$. flabellum) in March 2019. One ( $=6), 2(\mathrm{n}=14)$, or 3 $(\mathrm{n}=5)$ lesions were biopsied from each sea fan using titanium scissors to collect a $\sim 2 \mathrm{~cm}$ in diameter sample including a lesion and surrounding apparently healthy tissue. Sea fan biopsies were placed in Whirl-Pak bags until being processed on shore. The lesion in each biopsy was bisected and half of each was immersed in Z-Fix (Anatech) diluted 1:5 with seawater. Fungal culture and molecular identification were performed on the other half of the lesion for 30 samples. The other half of each lesion was again bisected, half being used for fungal culturing and the other for DNA extraction and subsequent molecular analyses. The lesions from Potato Bay were examined under a dissecting scope before being partitioned. To eliminate fungi present on the surface of sea fan fragments but not colonizing internal tissues, each fragment intended for culturing was surface sterilized in ethanol $70 \%$ for $30 \mathrm{~s}$ and then washed with filtered autoclaved seawater for another $30 \mathrm{~s}$.

\subsection{Histology and microscopic lesion categorization}

Formalin-fixed samples were scanned on an Epson Perfection V850 Pro scanner to facilitate microscopic identification of the purple spot location on histology 
slides and were then decalcified using Formical 2000 (StatLab). Once decalcified, the sample was processed routinely for histology, embedded in a planar orientation in paraffin wax (i.e. oriented so that sections were parallel to the face of the sea fan), sectioned at $4 \mu \mathrm{m}$, and stained with hematoxylin and eosin. Fontana-Masson stain was used on select sections where melanin deposition was suspected (Prophet et al. 1992). Histology sections were examined using a conventional light microscope (Olympus BX51) with the aid of a $45 \mathrm{~mm}$ Olympus U-Pot drop in polarizer and U-Ant analyzer. Where the lesioned area was not evident in the initial section, several sequential deeper sections were prepared from the paraffin-embedded tissue block. Photomicrographs were prepared with a digital camera (Olympus DP26) and cellSens Standard image analysis software.

Melanin deposits were yellow bands that stained black with Fontana-Masson stain, as previously described (Petes et al. 2003), and were associated with protein deposits that were extracellular homogenous eosinophilic laminae. Gorgonin deposits were also yellow bands but were distinguished from strictly melanin deposits by the presence of concentric lamellae, loculi, and birefringence with polarized light, similar to that observed in the gorgonin axial skeleton. Coenenchymal amoebocytosis was indicated by increased numbers of amoebocytes within the mesoglea. Amoebocyte encapsulation was dense congregations of amoebocytes, often bordering melanin and protein deposition, an etiologic agent, or calcified deposit. Periaxial cavitation and proteinosis were cavitated spaces adjacent to the axis, filled with lamellar to fibrillary material interspersed with lacy basophilic matrix, and many with hollow space suggestive of hard contents that were artefactually lost during sectioning.

Organisms identified with histology were classified according to morphologic characteristics. Barnacles were crustaceans (i.e. metazoan with striated muscle, segmented appendages, alimentary and reproductive viscera, and reserve inclusion cells) that resided within external calcareous plates. Algae were evident as filaments or mosaics of cuboidal to rectangular cells with a distinct cell wall. Fungi were identified as filamentous hyphae, with and without septation or branching. Cyanobacteria were filaments of concatenated trichomes. Labyrinthulomycetes were 1-10 $\mu \mathrm{m}$ ovoid magenta cells separated by clear space suggestive of mucus sheath (Burge et al. 2012, Tracy et al. 2018). The proportion of histologically identified organisms within the lesioned area of a biopsy relative to the non-lesioned area were compared using contingency tables and a McNemar's chi-square test, with significance level of $\mathrm{p} \leq 0.05$.

\subsection{Morphological fungal identification}

Fragments of the spot lesions were plated on Sabouraud dextrose agar (SDA) and glucose peptone yeast agar (GPYA, a standard medium for marine fungi) prepared with filtered, autoclaved seawater from the sampling location and incubated at $28^{\circ} \mathrm{C}$. The plates were monitored over a period of up to $1 \mathrm{mo}$ to allow for slower growing fungal species. Fungi were isolated in pure culture and where possible identified by morphology. Some colonies did not sporulate and morphology-based identification was not possible.

\subsection{Molecular fungal identification}

For molecular identification, fungal isolates were also transferred to liquid potato dextrose (PD) medium made with filtered, autoclaved seawater, and DNA was extracted from the mycelium pellet using the PowerSoil ${ }^{\circledR}$ DNA Isolation Kit (MoBio). For samples not sporulating in culture, DNA was extracted directly from the sea fan tissue. PCRs were used to amplify the internal transcribed spacer (ITS) regions (ITS1-5.8S-ITS2) of the fungal rDNA using the primers ITS-1 and ITS-4 (White et al. 1990). Tissues from 3 live barnacles were dissected from 3 different sea fans, all G. ventalina, during microscopic observation and placed directly into DNA lysis buffer. Total DNA was extracted using a GeneMATRIX DNA isolation kit (EURx) following the tissue protocol and used as templates in subsequent PCR reactions. DNA primers LCO-1490 and HCO-2198 (Folmer et al. 1994) were used to amplify the mitochondrial cytochrome c oxidase subunit I (COI) gene. PCR reactions contained a final volume of $20 \mu \mathrm{l}$ that consisted of: $1 \mu \mathrm{l}$ DNA template, $1.5 \mu \mathrm{l}$ each of forward and reverse primer, $0.2 \mu \mathrm{l}$ Taq polymerase, $2 \mu \mathrm{l} 10 \mathrm{X}$ buffer, $2 \mu \mathrm{l}$ dNTPs, and $11.8 \mu \mathrm{l}$ water. Thermocycling conditions were as follows: initial denaturation at $95^{\circ} \mathrm{C}$ for $4 \mathrm{~min}$, followed by 40 cycles of denaturation at $94^{\circ} \mathrm{C}$ for $30 \mathrm{~s}$, annealing $51^{\circ} \mathrm{C}$ for $1 \mathrm{~min}$, and extension at $72^{\circ} \mathrm{C}$ for $1 \mathrm{~min}$, followed by a final extension at $72^{\circ} \mathrm{C}$ for $7 \mathrm{~min}$. The PCR products were visualized by agarose gel electrophoresis, and DNA of the expected size were retrieved from the remaining PCR products using a GeneMATRIX PCR/DNA clean-up purification kit and sent to an ex- 
ternal lab for bidirectional sequencing using the same primers. Sequence chromatograms were checked for irregularities and BLAST searches performed to confirm a barnacle origin. Contiguous sequences were constructed using alignments made in ClustalX utilizing both forward and reverse sequence reads.

\section{RESULTS}

\subsection{Pathology}

On gross examination (facilitated by macro photography, dissecting microscope, and scanned images of biopsies), the multifocal purple spot lesions were devoid of polyps and had 1 of 4 morphologies (Fig. 1): (1) Pigmentation only $(n=4)$ : lesion was darker purple than surrounding tissues but otherwise unaltered (Fig. 1a); (2) pigmentation with branchlet expansion (n = 19): lesion was darker purple than surrounding tissues and branchlets were expanded and fused suggesting the addition of tissue components (Fig. 1b); (3) pigmentation with sessile masses $(\mathrm{n}=17)$ : lesion was darker purple than surrounding tissues and branchlets were focally merged with a slightly raised umbonate contour on one or both sides of the sea fan (Fig. 1C); (4) pigmentation with hard nodules $(\mathrm{n}=5)$ : lesion was darker purple than surrounding tissues and branchlets were adjoined by a nodule which spanned both sides of the sea fan, was tough to cut, and on cut surface was solid to gritty and homogenous dark purple (Fig. 1d).

Twelve of $17(70.6 \%)$ sessile masses had a 0.5$1 \mathrm{~mm}$ pore on one surface, most evident when examined with a dissecting microscope (Fig. 1e). Seven of $17(41.2 \%)$ sessile masses contained a live sessile barnacle (Infraclass Cirripedia), whereas 10/17 (58.8\%) contained gritty to pasty opaque yellow material (Fig. 1f). The pore was noticed in $4 / 7(57.1 \%)$ of sessile masses which contained a live barnacle. Barnacles resided within a calcified shell covered in coenenchyme of the sea fan. When examined with a dissecting microscope, cirri protruded through the pore and a mantel with a slit-shaped aperture could be observed, indicating a symmetrical (balanomorph) type of barnacle.

When compared with scanned biopsies, the purple spot lesions were not present in 5 of the 50 biopsies assessed with histology, despite intensive sectioning efforts, due to sample partitioning and small lesion size. These biopsies were excluded from histological and microbiological analysis. Histologically, Gorgonia multifocal purple spots lesions reflected an assort- ment of microscopic pathologies (Table 1, Fig. 2). The morphologic diagnoses presented in Table 1 represent the predominant microscopic alteration. There were no clear trends in predominant microscopic lesions among Gorgonia spp. (Tables S1 \& S2 in the Supplement at www.int-res.com/articles/suppl/ d141p079_supp.pdf). However, microscopic changes across all lesions included polyp loss $(45 / 45,100 \%)$, melanin deposition $(41 / 45,91.1 \%)$, coenenchymal amoebocytosis (38/45, 84.4\%; Fig. 2b), amoebocyte encapsulation (16/45, 35.6\%; Fig. 2c), periaxial cavitation and proteinosis $(14 / 45,31.1 \%$; Fig. 2 d), gorgonin deposition (13/45, 28.9\%; Figs. 2e-f), and polyp necrosis $(3 / 45,6.7 \%)$. Periaxial cavitation and proteinosis was always bordered by melanin deposition $(14 / 14,100 \%)$ and was often predominated by amoebocyte encapsulation $(7 / 14,50 \%)$. A pore was grossly evident in half of the $(7 / 14,50 \%)$ instances of periaxial cavitation and proteinosis, suggestive of a previous barnacle infection.

A variety of organisms were histologically identified within multifocal purple spots lesions and the adjacent apparently healthy tissue (Figs. 3 \& 4). Barnacles were identified in 7 biopsies from 5 sea fans and were identified using examination under the dissecting microscope in every case. Barnacles were only identified in G. ventalina, but otherwise there were no obvious trends in organisms identified among Gorgonia spp. (Tables S1 \& S2). Barnacles were only seen in pigmented lesions with sessile masses and were associated with microscopic morphologic diagnoses of melanin deposition (5/7, 71.4\%; Fig. 3c) and coenenchymal amoebocytosis (2/7, 28.6\%). Algae were identified in 23 biopsies from 17 sea fans. The odds of histologically identifying algae were 4 times greater for the lesioned area of the biopsy relative to the nonlesioned area $\left(\chi^{2}=4.3, \mathrm{p}=0.04\right)$. Intralesional algae involved all 4 gross lesion morphologies. They were always along the edge of the gorgonian axis (i.e. axial skeleton) and in the coenenchyme, associated with the microscopic morphologic diagnoses of gorgonin deposition (12/20, $60 \%)$, melanin deposition $(4 / 20,20 \%$; Fig. 3e), amoebocyte encapsulation $(3 / 20,15 \%)$, and coenenchymal amoebocytosis $(1 / 20,5 \%)$. Fungi were in 22 biopsies from 15 sea fans. Fungi were in the grossly pigmented areas of the biopsy in a minority of cases $(8 / 22,36 \%)$, but the proportion of histologically evident fungi did not significantly vary among lesioned and nonlesioned areas of the biopsy $\left(\chi^{2}=3.4, \mathrm{p}=\right.$ $0.07)$. Intralesional fungi involved all 4 gross morphologies. When within grossly pigmented areas of the biopsy, fungi were usually co-localized with 


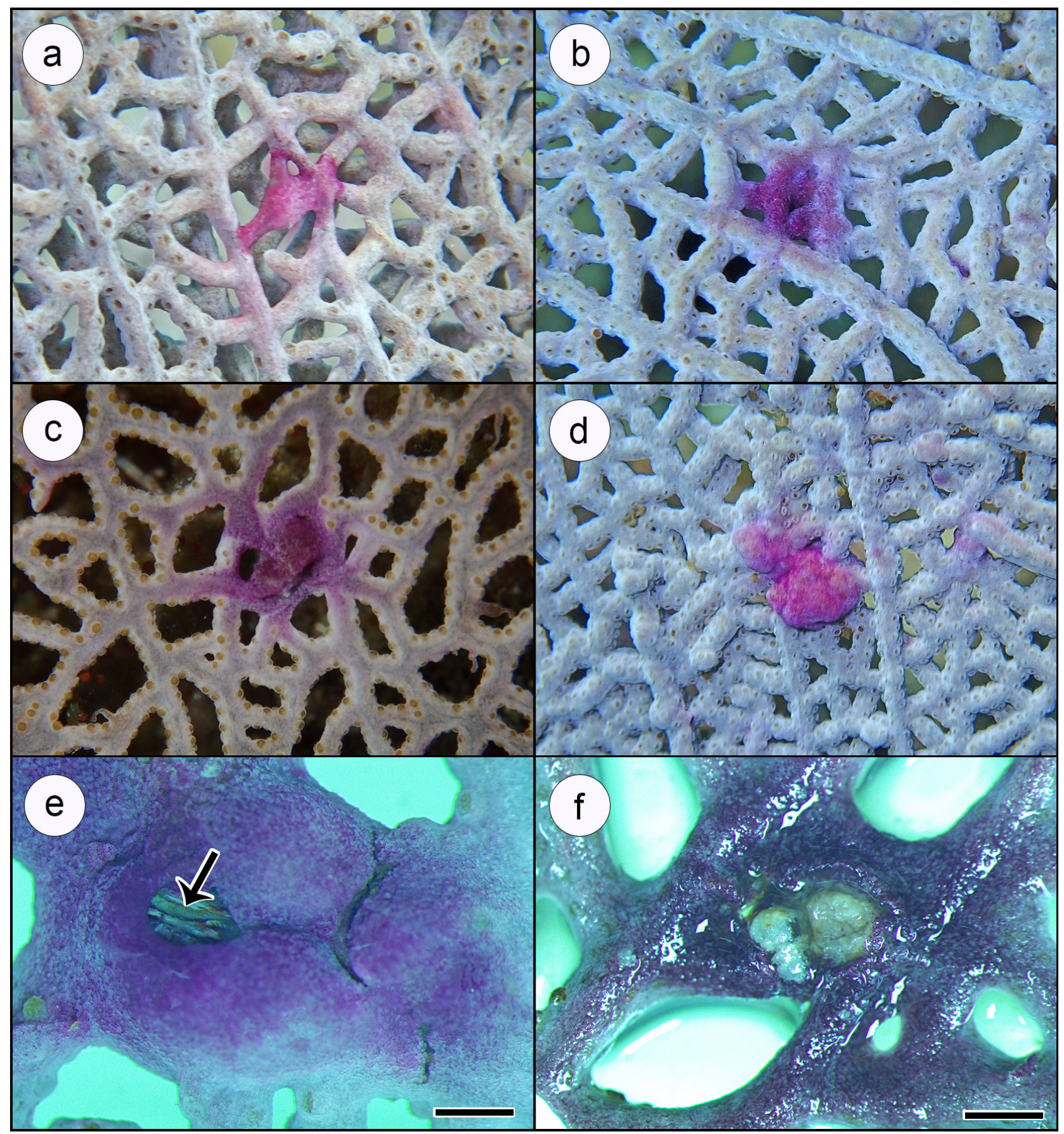

Fig. 1. (a-d) Subgross view of multifocal purple spots (MFPS) lesions in Gorgonia ventalina on shallow reefs of the coast of St. Kitts, West Indies. (a) Pigmentation only. Pigmentation with (b) branchlet expansion and fusion, (c) sessile masses, (d) hard nodules. (e) Pigmentation with a sessile mass viewed through a dissecting scope, showing a central pore through which the aperture of a symmetrical barnacle (arrow) is visible. Scale bar $=1 \mathrm{~mm}$. (f) Pigmentation with sessile mass viewed through a dissecting scope once transected, revealing a cavity filled with tan-yellow pasty material. Scale bar $=1 \mathrm{~mm}$

algae, which was the predominant organism $(6 / 8$, $75 \%$ ). They were either within the axis associated with coenenchymal amoebocytosis $(1 / 8,13 \%)$, melanin deposition (1/8, $13 \%$; Figs. 3a,b) or gorgonin de- position $(4 / 8,25 \%)$ or were within periaxial cavitation with proteinosis $(2 / 8,25 \%)$. Cyanobacteria were present in 11 biopsies from 8 sea fans (Fig. 3d) and located within grossly pigmented areas of the biopsy 
Table 1. Intralesional organisms and predominant microscopic morphologic diagnoses observed among the gross morphologies of Gorgonia multifocal purple spots lesions off St. Kitts

\begin{tabular}{|c|c|c|c|c|c|}
\hline Gross morphology & $\begin{array}{l}\text { Pigmentation } \\
\text { only }\end{array}$ & $\begin{array}{l}\text { Pigmentation } \\
\text { with branchlet } \\
\text { expansion }\end{array}$ & $\begin{array}{l}\text { Pigmentation } \\
\text { with sessile } \\
\text { masses }\end{array}$ & $\begin{array}{l}\text { Pigmentation } \\
\text { with hard } \\
\text { nodule }\end{array}$ & Total \\
\hline No. of biopsies & 4 & 19 & 17 & 5 & 45 \\
\hline \multicolumn{6}{|l|}{ Predominant microscopic lesion } \\
\hline Amoebocyte encapsulation & - & 5 & 4 & - & 9 \\
\hline Coenenchymal amoebocytosis & - & 3 & 3 & - & 6 \\
\hline Melanin deposition & 3 & 5 & 9 & - & 17 \\
\hline Gorgonin deposition & 1 & 6 & 1 & 5 & 13 \\
\hline \multicolumn{6}{|l|}{ Intralesional organisms } \\
\hline Barnacle & - & - & 7 & - & 7 \\
\hline Algae & 2 & 10 & 3 & 5 & 20 \\
\hline Cyanobacteria & - & 2 & 6 & 1 & 9 \\
\hline Fungi & 1 & 5 & 1 & 1 & 8 \\
\hline Labyrinthulid & - & 1 & - & - & 1 \\
\hline None & 2 & 5 & 4 & - & 11 \\
\hline
\end{tabular}

in most instances $(9 / 11,82 \%)$, but the proportion of histologically evident cyanobacteria did not significantly vary among lesioned and nonlesioned areas of the biopsy $\left(\chi^{2}=1.1, p=0.29\right)$. Intralesional cyanobacteria were within foci of periaxial cavitation with proteinosis $(8 / 9,89 \%)$ or co-localized with algae at the edge of the axis $(1 / 9,11 \%)$. They were associated with the microscopic morphologic diagnoses of amoebocyte encapsulation $(4 / 10,40 \%)$, melanin deposition $(4 / 10,40 \%)$, or gorgonin deposition $(2 / 10,20 \%)$. Labyrinthulomycetes were present in 7 biopsies from 3 sea fans. They were always intra-axial and associated with axial splitting and periaxial melanin deposition (Fig. 3f). The proportion of histologically evident labyrinthulomycetes was greater in the lesioned area of the biopsy than the nonlesioned area $\left(\chi^{2}=4.2, \mathrm{p}=\right.$ $0.04)$. In the only instance where they were within a lesion $(2 / 7,14.3 \%)$, they were associated with intraaxial fungi and were also in the adjacent grossly normal tissue associated with similar pathology. Other etiologies, present in 4 biopsies from different sea fans, were only within apparently healthy areas of biopsies and included unidentified metazoa (i.e. multicellular organism for which taxonomical classification was not histologically evident; $\mathrm{n}=2$ ), a mollusk, and a protist. An etiology was not histologically evident in 12 biopsies from 3 sea fans.

\subsection{Microbiology}

Penicillium was the most common genus isolated (12/30 lesions), whereas Montagnulaceae (1/30 lesions) and Curvaluria spp. (1/30 lesions) were uncommon. Penicillium spp. were further identified via
BLAST searches as $P$. chrysogenum. Sulcate velutinous colonies of Penicillium formed after 7-10 $\mathrm{d}$, with white borders, bluish green to dark green obverse and yellow reverse, and long dry chains of spherical conidia from brush-shaped conidiophores. Powdery to hairy black colonies with unbranched conidiophores and cigar-shaped conidia allowed presumptive identification of Curvaluria spp., molecularly identified as C. hawaiiensis. Montagnulaceae spp. did not sporulate in culture but were molecularly identified from the brownish gray to olivaceous colonies via BLAST searches. From 16 lesions, no definitive identification could be obtained either microscopically or molecularly.

\subsection{Molecular biology}

The COI gene from 3 barnacles was successfully sequenced, each having $658 \mathrm{bp}$ with primer binding sites removed, and are $>99 \%$ similar to each other. These sequences have been deposited in GenBank under the accession numbers MT089931-33. BLAST searches show that they are very closely related to barnacles from the genus Conopea, having 98-99\% identity to Conopea spp. taken from the Atlantic sea fans.

\section{DISCUSSION}

This study demonstrates that MFPS lesions of Gorgonia spp. are macroscopically, microscopically, and etiologically diverse. Because the pathology across MFPS lesions is so inconsistent, a case definition for a 


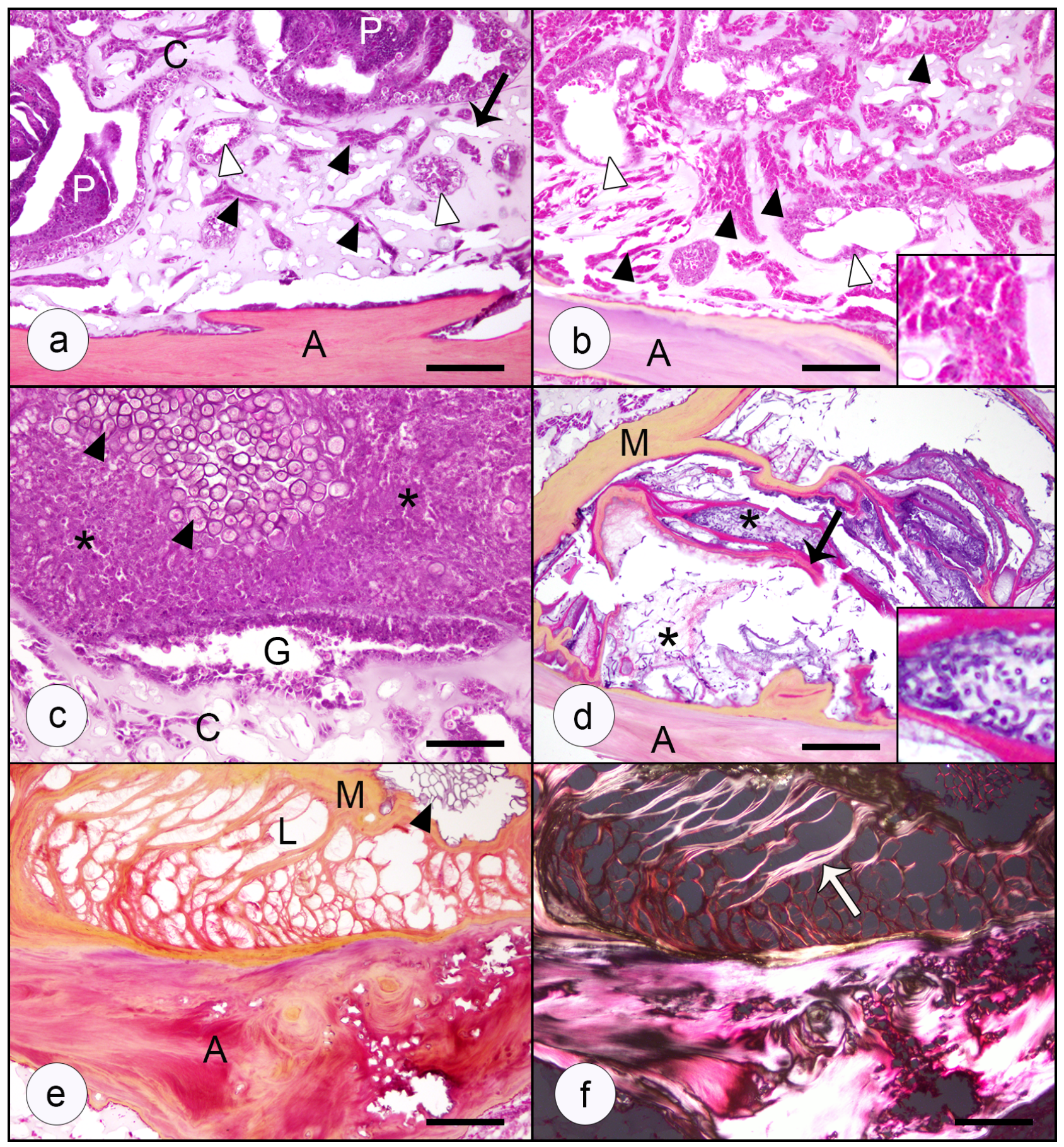

Fig. 2. Photomicrographs of multifocal purple spots lesions from Gorgonia spp. off St. Kitts. HE stain. (a) Biopsy from an apparently healthy G. ventalina for comparison showing gorgonian axis (A), polyps (P), and coenenchyme (C) containing gastrovascular canals (white arrowheads), clusters of amoebocytes (black arrowheads), and clear spaces where sclerites were dissolved during processing (arrow). (b) Severe coenenchymal amoebocytosis in G. ventalina. Number of amoebocytes (black arrowheads, inset) and size of their clusters within the coenenchyme are increased. Gastrovascular canals are dilated (white arrowheads). (c) Amoebocyte encapsulation in G. ventalina. Amoebocytes (*) are densely aggregated around algae (arrowheads). G: gastrovascular canal. (d) Melanin (M) and protein deposits (arrow) in G. ventalina adjacent to the gorgonian axis (A) with a hollow space containing fungal hyphae (*, inset). (e) Melanin (M) and gorgonin deposits in G. flabellum adjacent to the gorgonian axis (A) are separated by loculi (L). Black arrowhead designates algae. (f) Melanin and gorgonin deposition in G. flabellum. When viewed with polarized light, the area of melanin deposition is lamellar and birefringent (white arrow), similar to the adjacent axis. Scale bars $=(\mathrm{a}, \mathrm{b}) 70 \mu \mathrm{m}$, (c) $50 \mu \mathrm{m}$, (d) $100 \mu \mathrm{m},(\mathrm{e}, \mathrm{f}) 150 \mu \mathrm{m}$ 


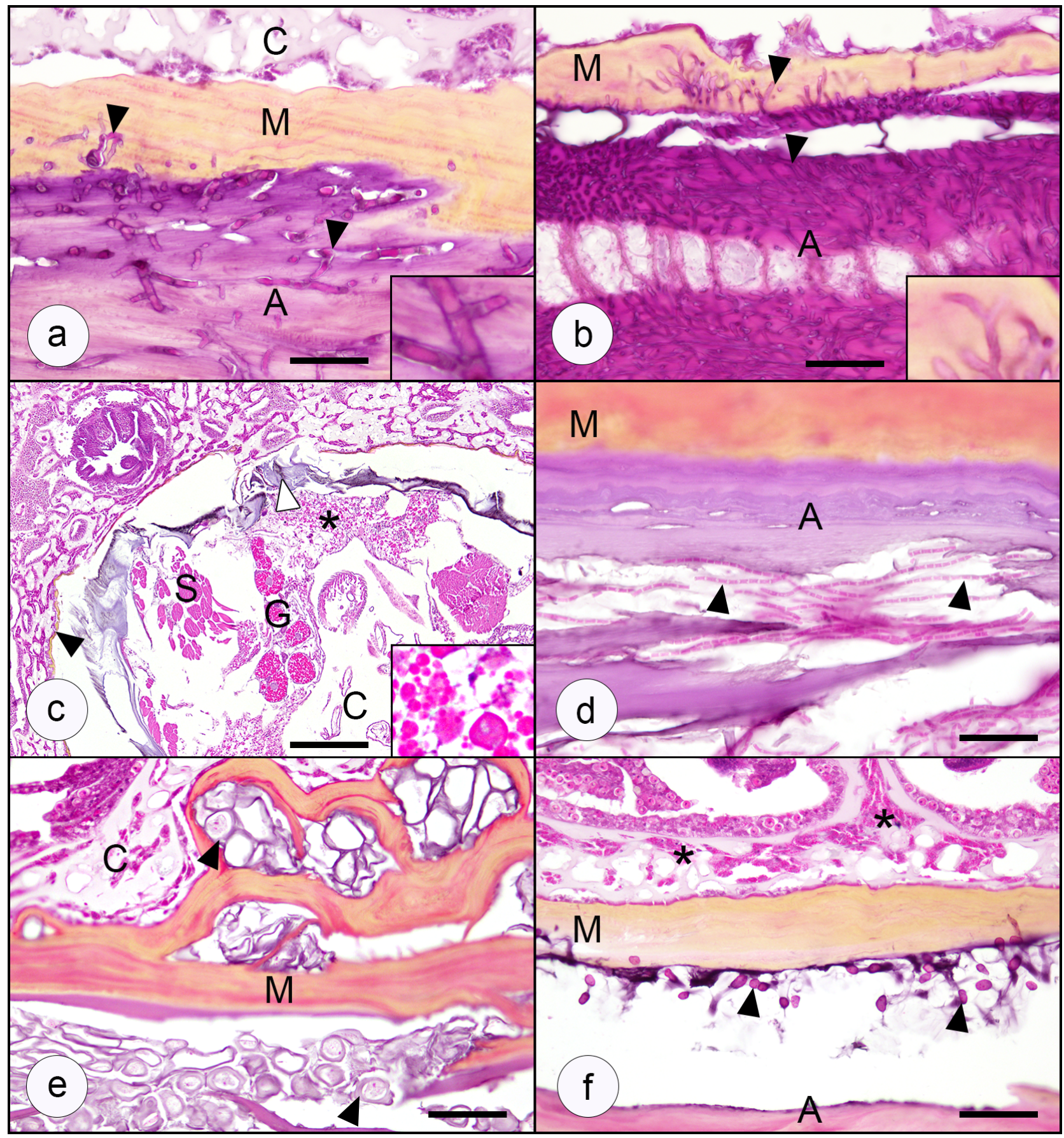

Fig. 3. Photomicrographs of organisms identified within biopsies of multifocal purple spots lesions from Gorgonia spp. off St. Kitts. (a,c-f) HE stain; (b) Periodic acid Schiff. (a) G. ventalina with one morphological form of fungal hyphae, consisting of septate hyphae with non-dichotomous branching (inset). Fungi (black arrowheads, inset) are within the gorgonian axis (A) and periaxial melanin deposition (M) but not coenenchyme (C). (b) G. flabellum with another morphological form of fungal hyphae characterized by smaller, slender and poorly septate hyphae showing dichotomous branching (black arrowheads, inset). A: gorgonian axis; M: periaxial melanin deposition. (c) G. ventalina with a barnacle, identified by the presence of a mantel (white arrowhead), skeletal muscle (S), gonad (G), cirri (C), and connective tissue containing reserve inclusion cells ( $*$, inset). Note polyp loss, and melanization (black arrowhead) in bordering coenenchyme. (d) G. ventalina with cyanobacteria (arrowheads) within the gorgonian axis (A) consisting of filaments of concatenated trichomes. M: periaxial melanin deposit. (e) G. ventalina with algae (black arrowhead) within periaxial melanin deposition (M) as indicated by angular cells with thick cell wall. C: coenenchyme. (f) G. ventalina with labyrinthulomycetes (black arrowheads) consisting of ovoid magenta cells separated by clear space. Note splitting of gorgonian axis (A), periaxial melanin deposition, and coenenchymal amoebocytosis (*). Scale bars = (a) $50 \mu \mathrm{m},(\mathrm{b}, \mathrm{d}) 20 \mu \mathrm{m},(\mathrm{c}) 200 \mu \mathrm{m},(\mathrm{e}, \mathrm{f}) 40 \mu \mathrm{m}$ 


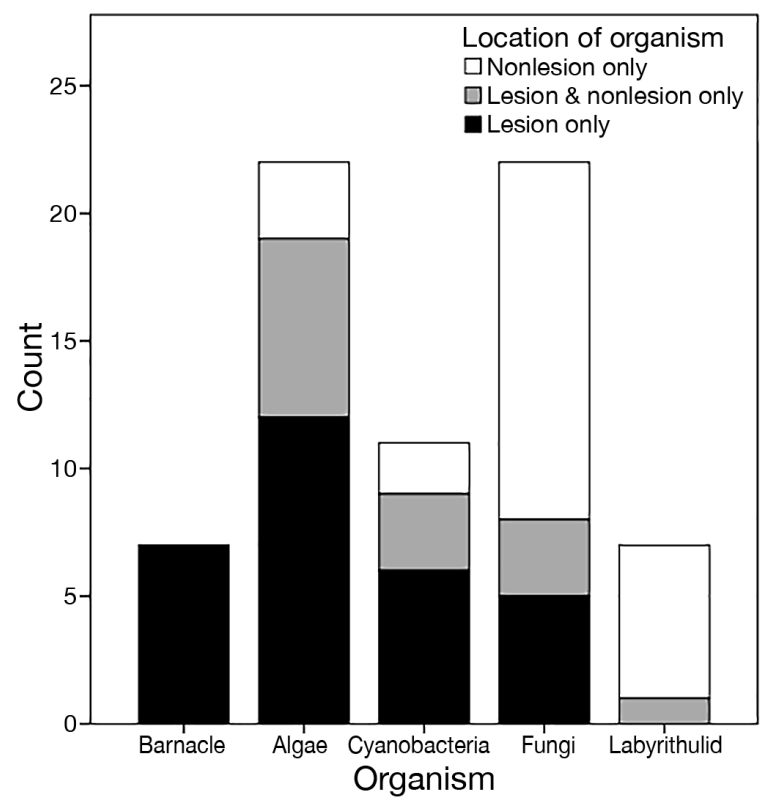

Fig. 4. Organisms histologically identified within biopsies of 45 multifocal purple spots lesions of Gorgonia spp. on St. Kitts and their localization to lesion (purple spot) and non-lesion (bordering grossly-normal) portions of the biopsy

specific disease could not be constructed. On the contrary, MFPS appears to comprise a highly nonspecific lesion pattern, and even subtle differences in gross pathology did not predict tissue alterations or etiologies recognized at the microscopic level.

Purple pigmentation in sea fans reflects an increased proportion of sclerites containing a carotenoid pigment and is a general response to injury typically resulting from biotic agents, rather than purely physical tissue trauma (Smith et al. 1998, Alker et al. 2004, Leverette et al. 2008). The purple pigmentation is not histologically evident because sclerites are dissolved by decalcification when processing for histology. However, this study shows that the purple pigmentation can be associated with several microscopic changes, especially melanin deposition, gorgonin deposition, coenenchymal amoebocytosis, and amoebocyte encapsulation. Melanin deposition occurs in association with axial fungal and Labyrinthulomycete infections (Petes et al. 2003, Burge et al. 2012), and coenenchymal amoebocytosis with axial fungal infections, cyanobacterial overgrowth, and increased environmental temperature (Mydlarz et al. 2008, Kiryu et al. 2015). In the present study, melanin deposition and coenenchymal amoebocytosis were also associated with encysted barnacles and periaxial algal infections. Taken together, these findings suggest that similar to purple pigmentation (Alker et al. 2004), melanin deposition and coenenchymal amoebocytosis are highly nonspecific responses to injury for Gorgonia spp.

Previous studies have implicated copepods and labyrinthulids as causing MFPS (Petes et al. 2003, Weil \& Rogers 2011, Ivanenko et al. 2017, Tracy et al. 2018), and this study also demonstrates the potential involvement of barnacles, algae, cyanobacteria, and fungi. Copepods were absent from our survey, emphasizing that they are not a necessary cause for the lesion. Labyrinthulids and fungi were mainly microscopically found in non-lesioned areas of sea fan biopsies, suggesting that they are opportunists associated with comparatively mild pathology. Moreover, the isolated fungi have previously been isolated from apparently healthy sea fan tissue (Soler-Hurtado et al. 2016). Although Penicillium chrysogenum is a common terrestrial fungus, it has also been frequently associated with other marine invertebrates including scleractinian corals and sponges (Yarden 2014), exemplifying its ubiquitous nature in marine environments. Nodular calcified deposits of gorgonin termed 'galls' or 'growth anomalies' encapsulate fungal and filamentous microalgae infections in sea fans (Morse et al. 1981, Weil et al. 2015), but in the present study, gorgonin deposition was most closely associated with algae infection (intralesional algae were present in 12/13 instances of gorgonin deposition). Perhaps some MFPS lesions represent early galls or growth anomalies, in which case, a proportion of lesions predominated by gorgonin deposition could be recognized grossly by the hard texture of the nodule $(5 / 13,38.5 \%)$.

Live Conopea spp. barnacles were found in 7 MFPS lesions in G. ventalina in this study. These have been described in several octocoral hosts of the Atlantic Ocean and Caribbean Sea, but not from the genus Gorgonia (Carrison-Stone et al. 2013), and are known as symbionts of gorgonians in the Pacific (Van Syoc et al. 2014). The present study shows that live barnacles are typically associated with minimal tissue pathology, limited to coenenchymal amoebocytosis and melanin deposition. However, it appears that in some instances periaxial cavitation and proteinosis is a consequence left by a deceased barnacle. This latter lesion often contained cyanobacteria or fungi, suggestive of opportunistic infections which may be more pathogenic than the initial barnacle.

The variety of organisms associated with the lesions examined by this study, and others (Burge et al. 2012, Ivanenko et al. 2017, Tracy et al. 2018), indicates that the macroscopic features used to diagnose MFPS are not specific to any one etiology. This is not surprising since the purple pigmentation response 
itself is nonspecific (Alker et al. 2004), and since corals in general have a limited spectrum of tissue responses to injury and therefore high likelihood that any one gross lesion morphology can be instigated by multiple etiologies (Work \& Meteyer 2014). From this regard, multifocal purple pigmentation is an acceptable gross morphological diagnosis for the lesion (Work \& Aeby 2006) but one that provides little value in terms of a disease name unless further defining characteristics can be demonstrated for the different etiologies involved (Work et al. 2008). It may be that many of the organism identified by our study are opportunists and a consequence to a consistent injurious event. However, a single underlying pathogen would not be expected to incite the wide spectrum of pathology we observed in MFPS lesions.

The conventional histological approach used by the present study is not a sensitive method for detecting some etiologic agents, especially those that might not be microscopically evident, such as viruses and toxins. A metagenomic approach to detect fungi and other microorganisms would be more sensitive than the methods used by our study. Therefore, it remains possible that other undetected etiologies are associated with or underlie MFPS lesions. In addition, the small size of MFPS lesions makes it difficult to ensure that microbial isolates represent the lesioned area rather than surrounding tissue. Ancillary techniques such as immunohistochemistry or laser capture microdissection could help confirm the identity of micro-organisms histologically recognized within MFPS lesions, and the present study identifies several genera of fungi which could be targeted by such methods.

In conclusion, this work emphasizes the importance of using a traditional biomedical approach that includes microscopic examination of tissues, rather than solely relying on a visual diagnosis, for accurate classification of coral diseases. To avoid confusion in the literature, we advocate refraining from using the term MFPS as a disease diagnosis without the use of ancillary diagnostics to clarify the etiology involved on a case-to-case basis (i.e. Sphaerippe MFPS, Conopea MFPS, algal MFPS, etc.) or until a more specific case definition can be devised for different etiologies.

Acknowledgements. This work was supported by an intramural grant from Ross University School of Veterinary Medicine, Center for Conservation Medicine and Ecosystem Health (Grant number 43007-2019). The authors are grateful for the histology performed by David Hilchie and for the assistance on sampling and sample processing provided by Alexandra Gutierrez, Victoria Vaughan, Anna Pleto, David Papanu, Nicole Atherley, and Kelsey Johnson.

\section{LITERATURE CITED}

Alker AP, Kim K, Dube DH, Harvell CD (2004) Localized induction of a generalized response against multiple biotic agents in aribbean sea fans. Coral Reefs 23:397-405

* Burge CA, Douglas N, Conti-Jerpe I, Weil E, Roberts S, Friedman CS, Harvell CD (2012) Friend or foe: the association of Labyrinthulomycetes with the Caribbean sea fan Gorgonia ventalina. Dis Aquat Org 101:1-12

Bythell J, Pantos O, Richardson L (2004) White plague, white band, and other 'white' diseases In: Rosenber E, Loya Y (eds) Coral health and disease. Springer-Verlag, Berlin, p 351-365

Carpenter KE, Abrar M, Aeby G, Aronson RB and others (2008) One-third of reef-building corals face elevated extinction risk from climate change and local impacts. Science 321:560-563

Carrison-Stone D, Syoc RV, Williams G, Simison WB (2013) Two new species of the gorgonian inhabiting barnacle, Conopea (Crustacea, Cirripedia, Thoracica), from the Gulf of Guinea. ZooKeys 270:1-20

* Couch CS, Weil E, Harvell CD (2013) Temporal dynamics and plasticity in the cellular immune response of the sea fan coral, Gorgonia ventalina. Mar Biol 160:2449-2460

*Folmer O, Black M, Hoeh W, Lutz R, Vrijenhoek R (1994) DNA primers for amplification of mitochondrial cytochrome $c$ oxidase subunit I from diverse metazoan invertebrates. Mol Mar Biol Biotechnol 3:294-299

* Harvell D, Jordán-Dahlgren E, Merkel S, Rosenberg E and others (2007) Coral disease, environmental drivers, and the balance between coral and microbial associates. Oceanography (Wash DC) 20:172-195

IUCN (2019) The IUCN Red List of Threatened Species. Version 2019-3. www.iucnredlist.org.

Ivanenko VA, Nikitin M, Hoeksema B (2017) Multiple purple spots in the Caribbean sea fan Gorgonia ventalina caused by parasitic copepods at St. Eustatius, Dutch Caribbean. Mar Biodivers 47:79-80

Jackson J, Donovan M, Cramer K, Lam V (2014) Status and trends of Caribbean coral reefs: 1970-2012. Global Coral Reef Monitoring Network, IUCN, Gland. https://portals. iucn.org/library/efiles/documents/2014-019.pdf

KKiryu Y, Landsberg JH, Peters EC, Tichenor E, Burleson C, Perry N (2015) Pathological effects of cyanobacteria on sea fans in southeast Florida. J Invertebr Pathol 129:13-27

KLeverette CL, Warren M, Smith MA, Smith GW (2008) Determination of carotenoid as the purple pigment in Gorgonia ventalina sclerites using raman microscopy. Spectrochim Acta A 69:1058-1061

Morse DE, Morse A, Duncan H, Trench RK (1981) Algal tumors in the Caribbean octocorallian, Gorgonia ventalina: II. Biochemical characterization of the algae, and first epidemiological observations. Bull Mar Sci 31:399-409

* Mydlarz LD, Holthouse SF, Peters EC, Harvell CD (2008) Cellular responses in sea fan corals: granular amoebocytes react to pathogen and climate stressors. PLOS ONE 3:e1811

* Petes LE, Harvell CD, Peters EC, Webb MAH, Mullen KM (2003) Pathogens compromise reproduction and induce melanization in Caribbean sea fans. Mar Ecol Prog Ser 264:167-171

Prophet EB, Mills B, Arrington JB, Sobin LH (1992) Laboratory methods in histotechnology. American Registry of Pathology, Armed Forces Institute of Pathology, Washington, DC 
Rodríguez-Martínez RE, Jordán-Garza AG, Jordán-Dahlgren E (2016) Low regeneration of lesions produced by coring in Orbicella faveolata. PeerJ 4:e1596

Smith G, Harvel C, Kim K (1998) Response of sea fans to infection with Aspergillus sp. (fungi). Rev Biol Trop 46: 205-208

Soler-Hurtado MM, Sandoval-Sierra JV, Machordom A, Diéguez-Uribeondo J (2016) Aspergillus sydowii and other potential fungal pathogens in gorgonian octocorals of the Ecuadorian Pacific. PLOS ONE 11:e0165992

Tracy AM, Weil E, Harvell CD (2018) Octocoral co-infection as a balance between host immunity and host environment. Oecologia 186:743-753

Tsounis G, Edmunds PJ (2017) Three decades of coral reef community dynamics in St. John, USVI: a contrast of scleractinians and octocorals. Ecosphere 8:e01646

Van Syoc RJ, Carrison-Stone D, Madrona L, Williams GC (2014) Barnacle symbionts of gorgonian sea fans, description of seven new species (Archaeobalanidae: Cirripedia) from the Philippines, including a key to the western Pacific species of Conopea. In: Williams GC, Gosliner TM (eds) The coral triangle, the 2011 Hearst Philippine Biodiversity Expedition. California Academy of Sciences, San Francisco, CA, p 171-211

Weil E, Hooten A (2008) Underwater cards for assessing coral health on Caribbean reefs. GEF-coral reef targeted research program, 2008. CRTR Program Project Agency

Editorial responsibility: Esther Peters,

Fairfax, Virginia, USA
Weil E, Rogers CS (2011) Coral reef diseases in the AtlanticCaribbean. In: Dubinsky Z, Stambler N (eds) Coral reefs: an ecosystem in transition. Springer, Dordrecht, p 465-491

Weil E, Rogers CS, Croquer A (2015) Octocoral diseases in a changing ocean. In: Rossi S, Bramanti L, Gori A, Orejas Saco del Valle C (eds) Marine animal forests: the ecology of benthic biodiversity hotspots. Springer International Publishing, Cham, p 1-55

White TJ, Bruns T, Lee SY, Taylor JH (1990) Amplification and direct sequencing of fungal ribosomal RNA genes for phylogenetics. In: Innis A, Gelfand DH, Sninsky JJ (eds) PCR protocols: a guide to methods and applications. Academic Press, San Diego, CA, p 315-322

Wilkinson C (2008) Status of coral reefs of the world: 2008. Global Coral Reef Monitoring Network and Reef and Rainsforest Research Center, Townsville

WWork TM, Aeby GS (2006) Systematically describing gross lesions in corals. Dis Aquat Org 70:155-160

* Work T, Meteyer C (2014) To understand coral disease, look at coral cells. EcoHealth 11:610-618

* Work TM, Richardson LL, Reynolds TL, Willis BL (2008) Biomedical and veterinary science can increase our understanding of coral disease. J Exp Mar Biol Ecol 362:63-70

* Yarden O (2014) Fungal association with sessile marine invertebrates. Front Microbiol 5:228

Submitted: April 15, 2020; Accepted: August 3, 2020

Proofs received from author(s): September 7, 2020 